\title{
Association between Perceived Built Environment and Prevalent Hypertension among South African Adults
}

\author{
Pasmore Malambo, ${ }^{1}$ Andre P. Kengne, ${ }^{2}$ Estelle V. Lambert, ${ }^{3}$ \\ Anniza De Villers, ${ }^{2}$ and Thandi Puoane ${ }^{1}$ \\ ${ }^{1}$ School of Public Health, University of Western Cape, Robert Sobukwe Road, Bellville, Cape Town 7535, South Africa \\ ${ }^{2}$ Noncommunicable Disease Unit, South African Medical Research Council, Francie van Zijl Drive, Parow Valley, \\ P.O. Box 19070, Tygerberg, Cape Town 7505, South Africa \\ ${ }^{3}$ Division of Exercise Science and Sports Medicine, Department of Human Biology, Faculty of Health Sciences, \\ University of Cape Town, P.O. Box 115, Newlands, Cape Town 7725, South Africa
}

Correspondence should be addressed to Pasmore Malambo; pmalambo@hotmail.com

Received 23 February 2016; Accepted 19 May 2016

Academic Editor: Masahito Fushimi

Copyright ( 92016 Pasmore Malambo et al. This is an open access article distributed under the Creative Commons Attribution License, which permits unrestricted use, distribution, and reproduction in any medium, provided the original work is properly cited.

\begin{abstract}
Introduction. The association between perceived built environmental attributes and hypertension among adults has received little attention in an African context. We investigated the association between the perceived built environment and prevalent hypertension in adult South Africans. Method. A cross-sectional study was conducted using 2008-2009 Prospective Urban Rural Epidemiology data among South African $(n=671)$ adults aged $\geq 35$ years. Perceived built environment was assessed using the neighborhood environment walkability scale questionnaire. Prevalent hypertension was defined as previously diagnosed by a physician, screen-detected hypertension as $\geq 140 / 90 \mathrm{mmHg}$, and a combination of both as any hypertension. Logistic regressions were applied for analyses. Results. In crude logistic regressions, self-reported hypertension was associated with land use mixdiversity, street connectivity, infrastructure for walking/cycling, aesthetics, traffic, and crime. In adjusted model, land use mixdiversity was significantly associated with self-reported hypertension. In similar multivariable models, the direction and magnitude of the effects were mostly similar to the outcomes of "screen-detected hypertension" which was further predicted by perceived lack of safety from traffic. Conclusion. Perceived built environment attributes were significantly associated with hypertension. This has relevance to population-based approaches to hypertension prevention and control.
\end{abstract}

\section{Background}

Hypertension is estimated to cause 7.5 million premature deaths, accounting for $12.8 \%$ of all global deaths annually [1]. Hypertension is associated with an increased risk of morbidity and mortality from cardiovascular disease (CVD) [2], with high event rates occurring in low- and middle-income countries [3] and greater than 50\% increased prevalence expected from 2000-2025 [4]. South Africa is experiencing a demographic and epidemiological transition with an increase in the population aged 50 years and older and rising prevalence of noncommunicable diseases [5]. Hypertension is a common condition in South Africa and is a risk factor for heart attacks and stroke [6]. In 2000, high blood pressure was estimated to have caused 9\% $(n=46888)$ of all deaths and 2.4\% $(n=390860)$ of all disability-adjusted life years [7] among South Africans. According to van de Vijver et al. [8], hypertension has been regarded as a disease of affluence but this has changed drastically in the last two decades with average blood pressure now higher in Africa than in the Global North and the prevalence of hypertension increasing among poor sections of the society. For example, in a recent systematic review and meta-analysis conducted in Sub-Saharan Africa, the prevalence of hypertension ranged from $15 \%$ to $70 \%$ [9].

Various risk factors have been associated with hypertension $[10,11]$. However, in order to reduce the burden of CVD risk factors, environmental interventions have become 
increasingly recognized as necessary approaches to support behavior change [12]. The fundamental attributes of built environments and community design $[13,14]$ have been linked with increased risk of hypertension and cardiovascular events [15], but only a few studies have evaluated these relationships in an African context [16]. Thus, this study evaluates the association between perceived built environment attributes and the prevalence of hypertension in South African adults in both an urban (Cape Town) and a rural (Mount Frere) context. Our focus was on the general perception of built environment attributes rather than components of it.

\section{Methods}

2.1. Study Population. This cross-sectional study uses data from Cape Town (urban) and Mount Frere (rural) sites of the global Prospective Urban Rural Epidemiology (PURE) study. During baseline evaluation conducted in 2008-2009, a random sample of both male and female adults was selected from well-established rural (Mount Frere, $N=$ 1003) and urban (formal settlements in Cape Town, $N=$ 1061) communities in South Africa. The inclusion criteria for participants were those (1) aged 35-70 years, (2) living within identified household, and having (3) no disability that precluded walking.

2.2. Ethical Considerations. The study was conducted according to the Helsinki principles [17]. The Senate Higher Degrees committee, Research Committees of the University of the Western Cape, South Africa, and Population Health Research Institute, Canada, approved the study (Registration \#13/6/18). A consent form was signed by all the participants.

2.3. Data Collection. Participants were interviewed in the language of their choice. Structured, sociodemographic, and lifestyle questionnaires that were developed or adapted and standardized for the international PURE study were used [18]. Physical examination included anthropometric measures [19]. The NEWS was used to assess perceived neighborhood environment.

2.4. Sociodemographic Characteristics. Sociodemographic information on age, sex, marital status, education level, location, and occupation was elicited from participants. Participants' age was grouped into 3 categories: 35 to 44 years, 45 to 54 years, and 55 and above. Marital status was classified as single, married, and divorced. Education level was classified as primary, secondary, and tertiary education. Occupation was categorized into 2 groups: less skilled (artisan, trader, farmer, etc.) and homemaker. Smoking was defined as former smoker, current smoker, and never smoked. In this analysis, former and current smoker were categorized as "yes" and never smoker was categorized as "no." Alcohol use was treated in the same way as smoking.
2.5. Anthropometric and Biological Measures. Body height and body weight were determined by standard anthropometric methods. Height was measured to the nearest $0.1 \mathrm{~cm}$ in bare feet with participants standing upright using a portable tape measure. Weight was measured to the nearest kilogram, with participants lightly dressed using a portable bathroom weighing scale calibrated (Soehnle, Germany) from 0 to $120 \mathrm{~kg}$. Body mass index (BMI) was calculated as weight (kg) divided by the square of the height $\left(\mathrm{m}^{2}\right)$. The World Health Organization [20] principal cut-off points for BMI were used to create the categories: underweight $\left(<18.5 \mathrm{~kg} / \mathrm{m}^{2}\right)$, normal weight $\left(18.5-<25 \mathrm{~kg} / \mathrm{m}^{2}\right)$, overweight $\left(25-<30 \mathrm{~kg} / \mathrm{m}^{2}\right)$, and obese $\left(>30 \mathrm{~kg} / \mathrm{m}^{2}\right)$.

2.6. Blood Pressure Measurement and Definition of Hypertension. Trained staff measured blood pressure using an OMRON 711 automated device with the appropriate cuff size for the measured mid-upper-arm circumference and after the subject had been seated at rest for at least 10 minutes. Two readings were made 3-4 minutes apart and the averaged reading was used for the definition of hypertension [21]. Additionally, hypertension was defined as previously diagnosed hypertension by a physician based on a positive answer to the question "have you been diagnosed with hypertension?" for self-reported hypertension. Screen-detected hypertension was defined as blood pressure $\geq 140 / 90 \mathrm{mmHg}$ among those with no prior diagnosis of hypertension, while "any hypertension" was based on the presence of self-reported or screendetected hypertension.

2.7. Self-Reported Physical Activity. The long version of the International Physical Activity Questionnaire (IPAQ), which is self-administered, was used to measure sedentary, light, moderate, and vigorous intensity activities and walking in terms of the frequency (days/week) and duration (min/day) in the last 7 days. Only activities lasting for 10 consecutive minutes or more were considered [22]. A cut-off point of 150 minutes per week was used to classify subjects as sufficiently physically active or physically inactive [23] and used previously [22]. Acceptable reliability and validity of IPAQ have been reported elsewhere [24].

2.8. Perceived Built Environment. The neighborhood environment walkability scale (NEWS) questionnaire was used to obtain perceived neighborhood attributes for each participant. Participants were instructed to consider neighborhood as the area within a $10-15$ min walk from their home and answered questions pertaining to the following subscales: (a) land use mix-diversity (having commercial destinations within walking distance, 10 items); (b) land use-access (the ease of access from one's home to activity opportunities, 4 items); (c) streets connectivity (the number of 3-and 4-way intersections in a an area/total area in squared kilometers, 3 items); (d) infrastructure for walking and cycling (the maintenance, existence of sidewalks, and layout of roads, 3 items); (e) aesthetics (attractions and cleanness of neighborhoods, 3 items); (f) safety from traffic (traffic condition and its negative effect on environment, 3 items); (g) safety from crime (perceived 
TABLE 1: Subscales and sample item description from the neighborhood environment walkability scale.

\begin{tabular}{|c|c|c|}
\hline Item number & Subscale & Sample item description \\
\hline 01 & Land use mix-diversity & $\begin{array}{l}\text { About how long would it take to get from your home to the nearest businesses or } \\
\text { facilities if you walked to them? } \\
\text { (i) Groceries } \\
\text { (ii) Clothes shop } \\
\text { (iii) Fruits and vegetables } \\
\text { (iv) Restaurant } \\
\text { (v) Bank } \\
\text { (vi) Video shop }\end{array}$ \\
\hline 02 & Land use-access & $\begin{array}{l}\text { I can do most of my shopping at local stores } \\
\text { Stores are within easy walking distance of my home } \\
\text { There are many places to go within easy walking distance of my home } \\
\text { It is easy to walk to a transit stop from my home }\end{array}$ \\
\hline 03 & Streets connectivity & $\begin{array}{l}\text { The distance between intersections in my neighborhood is usually short } \\
\text { There are many four-way intersections in my neighborhood } \\
\text { There are many alternative routes for getting from place to place in my } \\
\text { neighborhood }\end{array}$ \\
\hline 04 & Infrastructure for walking/cycling & $\begin{array}{l}\text { There are sidewalks on most of the streets in my neighborhood } \\
\text { The sidewalks in my neighborhood are well maintained } \\
\text { There is a grass/dirt strip that separates the streets from the sidewalks in my } \\
\text { neighborhood }\end{array}$ \\
\hline 05 & Aesthetics & $\begin{array}{l}\text { Trees give shade for the sidewalks in my neighborhood } \\
\text { There are many interesting things to look at while walking in my neighborhood } \\
\text { My neighborhood is generally free from litter }\end{array}$ \\
\hline 06 & Safety from traffic & $\begin{array}{l}\text { There is so much traffic along the street I live on that it makes it difficult or } \\
\text { unpleasant to walk in my neighborhood } \\
\text { There is so much traffic along nearby streets that it makes it difficult or unpleasant } \\
\text { to walk in my neighborhood } \\
\text { The crosswalks in my neighborhood help walkers feel safe crossing busy streets }\end{array}$ \\
\hline 07 & Safety from crime & $\begin{array}{l}\text { My neighborhood streets are well lit at night } \\
\text { The crime rate in my neighborhood makes it unsafe to go on walks during the day } \\
\text { The crime rate in my neighborhood makes it unsafe to go on walks at night }\end{array}$ \\
\hline
\end{tabular}

fear in the neighborhood, 3 items). All items except for the land use mix-diversity subscale were scaled from 1 (strongly disagree) to 4 (strongly agree), with higher scores indicating more favorable rating. For statistical analyses, however, we collapsed these variables into two categories of agree $(1=1$ or 2 ) or disagree ( $2=3$ or 4 ) [25]. Land use mix-diversity was assessed by asking for the time taken to walk from home to various types of stores and facilities, with responses ranging from 1- to 5-minute walking distance (coded as 5) to $\geq 30$ minute walking distance (coded as 1). The land use mixdiversity variables were dichotomized into " $\leq 20$ minutes" and " $\geq 21$ minutes" for analyses purposes [26]. Higher scores on land use mix-diversity indicated closer average temporal proximity. All subscale scores were calculated as the mean across the subscale items. Items with inverse interpretation were reverse coded for analyses, with higher values reflecting environmental attributes hypothesized to be conducive to physical activity [27]. Sample items from the NEWS are described in Table 1. NEWS has been shown to be both a valid and reliable means of assessment [28].

2.9. Statistical Analysis. The starting sample comprised 1016 participants of whom 345 were excluded for unacceptable missing data [29] after merging of three datasets. Therefore, the final analytic sample comprised 671 participants with a complete NEWS questionnaire. Data analysis used SPSS ${ }^{\circledR}$ version 22 for Windows (IBM Corp., Armonk, New York). Descriptive statistics were computed for all variables. The Chi squared test was used to compare sociodemographic characteristics selected CVD risk factors and built environment attributes by gender. Logistic regressions were used to investigate the determinants of hypertension. In order to identify factors associated with hypertension, two models were fitted. Model 1 (crude odd ratios) determined the association between sociodemographic characteristics, selected CVD risk factors, and built environment attributes by gender. Model 2 (adjusted odd ratios) determined the association between built environment attributes after adjusting for sociodemographic (sex, age, location, and education status), $\mathrm{BMI}$, and physical activity variables. The main analyses were focused on the outcome of "self-reported hypertension." However, in secondary analyses we also explored the effects on the outcomes of "screen-detected hypertension" and "any hypertension.”

\section{Results}

3.1. General Characteristics of the Participants. Table 2 depicts the overall sociodemographic characteristics, selected CVD risk factors, and perceived built environment attributes of 
TABLE 2: Sociodemographic characteristics of participants.

\begin{tabular}{|c|c|c|c|c|}
\hline Variable & $\begin{array}{c}\text { Female }(n=510) \\
\text { Number }(\%)\end{array}$ & $\begin{array}{c}\text { Male }(n=161) \\
\text { Number }(\%)\end{array}$ & $p$ value & $\begin{array}{l}\text { All }(n=671) \\
\text { Number }(\%)\end{array}$ \\
\hline \multicolumn{5}{|l|}{ Gender } \\
\hline Female & & & & $510(76.0)$ \\
\hline Male & & & & $161(24.0)$ \\
\hline Age & & & 0.251 & \\
\hline $35-44$ & $173(33.9)$ & $48(29.8)$ & & $221(32.9)$ \\
\hline $45-54$ & $166(32.5)$ & $63(39.1)$ & & $229(34.1)$ \\
\hline $55+$ & $171(33.5)$ & $50(31.1)$ & & $221(32.9)$ \\
\hline Marital status & & & 0.001 & \\
\hline Single & $209(41.0)$ & $56(34.8)$ & & $265(39.1)$ \\
\hline Married & $192(37.6)$ & $85(52.8)$ & & $277(41.3)$ \\
\hline Divorce & $109(21.4)$ & $20(12.4)$ & & $129(19.2)$ \\
\hline Education status & & & 0.140 & \\
\hline Primary & $17(3.3)$ & $11(6.8)$ & & $28(4.2)$ \\
\hline Secondary & $471(92.4)$ & $142(88.2)$ & & $613(91.4)$ \\
\hline Tertiary & $22(4.3)$ & $8(5.0)$ & & $30(4.5)$ \\
\hline Occupation & & & 0.118 & \\
\hline Less skilled & $75(14.7)$ & $129(80.1)$ & & $564(84.1)$ \\
\hline Homemaker & $435(85.3)$ & $32(19.9)$ & & $107(15.9)$ \\
\hline Ethnicity & & & 0.240 & \\
\hline African & $506(99.2)$ & $158(98.1)$ & & $664(99.0)$ \\
\hline Coloured & $4(0.8)$ & $3(1.9)$ & & $7(1.0)$ \\
\hline Location & & & 0.915 & \\
\hline Urban & $221(43.3)$ & $69(42.9)$ & & $290(43.2)$ \\
\hline Rural & $289(56.7)$ & $92(57.1)$ & & $381(56.8)$ \\
\hline \multicolumn{5}{|l|}{ Selected CVD risk factors } \\
\hline \multicolumn{5}{|l|}{ Blood pressure $(M \pm S D)^{*}$} \\
\hline Systolic blood pressure (mmHg) & $142.2(25.7)$ & $140.5(19.4)$ & 0.838 & $141.8(24.2)$ \\
\hline Diastolic blood pressure (mmHg) & $92.7(15.2)$ & $89.3(12.2)$ & 0.004 & $91.9(14.6)$ \\
\hline Self-reported hypertension & & & $<0.001$ & \\
\hline No & $338(66.3)$ & $134(83.2)$ & & $472(70.3)$ \\
\hline Yes & $172(33.7)$ & $27(16.8)$ & & $199(29.7)$ \\
\hline Screen-detected hypertension & & & $<0.001$ & \\
\hline Normotension & $186(55.0)$ & $38(28.4)$ & & $224(47.5)$ \\
\hline Hypertension & $152(45.0)$ & $96(71.6)$ & & $248(52.5)$ \\
\hline Any hypertension & & & 0.003 & \\
\hline No & $186(36.5)$ & $38(23.6)$ & & $224(33.4)$ \\
\hline Yes & $234(63.5)$ & $123(76.4)$ & & $447(66.6)$ \\
\hline Self-reported diabetes & & & 0.469 & \\
\hline No & $466(91.4)$ & $150(93.2)$ & & $616(91.8)$ \\
\hline Yes & $44(8.6)$ & $11(6.8)$ & & $55(8.2)$ \\
\hline BMI category & & & $<0.001$ & \\
\hline Normal & $100(19.6)$ & $107(66.4)$ & & $207(30.8)$ \\
\hline Overweight & $127(24.9)$ & $23(14.3)$ & & $150(22.4)$ \\
\hline Obese & $283(55.5)$ & 31 (19.3) & & $314(46.8)$ \\
\hline Smoking & & & $<0.001$ & \\
\hline No & $437(85.7)$ & $70(43.5)$ & & $507(75.6)$ \\
\hline Yes & 73 (14.3) & $91(56.5)$ & & $164(24.4)$ \\
\hline Alcohol use & & & $<0.001$ & \\
\hline No & $448(87.8)$ & $73(45.3)$ & & $521(77.6)$ \\
\hline Yes & $62(12.2)$ & $88(54.7)$ & & $150(22.4)$ \\
\hline
\end{tabular}


TABLE 2: Continued.

\begin{tabular}{|c|c|c|c|c|}
\hline Variable & $\begin{array}{c}\text { Female }(n=510) \\
\text { Number }(\%)\end{array}$ & $\begin{array}{c}\text { Male }(n=161) \\
\text { Number }(\%)\end{array}$ & $p$ value & $\begin{array}{l}\text { All }(n=671) \\
\text { Number }(\%)\end{array}$ \\
\hline Physical activity levels & & & 0.718 & \\
\hline$<150 \mathrm{~min} /$ week & $152(30.8)$ & $52(32.3)$ & & $209(31.1)$ \\
\hline$>150 \mathrm{~min} /$ week & $353(69.2)$ & $109(67.7)$ & & $462(68.9)$ \\
\hline \multicolumn{5}{|c|}{ Perceived built environment attributes } \\
\hline Land use mix-diversity & & & 0.110 & \\
\hline$\leq 20 \mathrm{~min}$ & $42(8.2)$ & $20(12.4)$ & & $62(9.2)$ \\
\hline$\geq 21 \mathrm{~min}$ & $468(91.8)$ & $141(87.6)$ & & $609(90.8)$ \\
\hline Land use mix-access & & & 0.160 & \\
\hline Disagree & $381(74.7)$ & $129(80.1)$ & & $510(76.0)$ \\
\hline Agree & $129(25.3)$ & $32(19.9)$ & & $161(24.0)$ \\
\hline Street connectivity & & & 0.612 & \\
\hline Disagree & $227(44.5)$ & $68(42.2)$ & & $295(44.0)$ \\
\hline Agree & $283(55.5)$ & $93(57.8)$ & & $376(56.0)$ \\
\hline Infrastructure for walking/cycling & & & 0.091 & \\
\hline Disagree & $248(48.6)$ & $66(41.0)$ & & $314(46.8)$ \\
\hline Agree & $262(51.4)$ & $95(59.0)$ & & $357(53.2)$ \\
\hline Aesthetics & & & 0.082 & \\
\hline Disagree & $318(62.4)$ & $88(54.7)$ & & $406(60.5)$ \\
\hline Agree & $192(37.6)$ & $73(45.3)$ & & $265(39.5)$ \\
\hline Safety from traffic & & & 0.490 & \\
\hline Disagree & $263(51.6)$ & $78(48.8)$ & & $341(50.8)$ \\
\hline Agree & $247(48.4)$ & $83(51.6)$ & & $330(49.2)$ \\
\hline Safety from crime & & & 0.172 & \\
\hline Disagree & $234(45.9)$ & $64(39.8)$ & & $298(44.4)$ \\
\hline Agree & $176(54.1)$ & $97(60.2)$ & & $373(55.6)$ \\
\hline
\end{tabular}

SD: standard deviation; ${ }^{*}$ subsample of 472 participants after excluding those with self-reported hypertension.

participants. Out of 671 participants, $76.0 \%$ were women, $32.9 \%$ were aged $35-44$ years, and $56.8 \%$ were from the rural site. Overall, $41.3 \%$ of the participants were married and marital status differed by gender $(p=0.001)$. The study population comprised $99.0 \%$ Africans and $1.0 \%$ mixedancestry participants. There were significant gender differences in the distribution of BMI categories, smoking, and alcohol use (all $p<0.001$ ). The majority (68.9\%) of the participants met physical activity guidelines and there was no gender difference $(p=0.718)$. Overall the distribution of perceived built environment attributes was as follows: land diversity ( $\geq 20 \mathrm{~min}$ ) $90.8 \%$, land access (disagreed) $76.0 \%$, street connectivity (agreed) $56.0 \%$, walking/cycling (agreed) $53.2 \%$, aesthetics (disagreed) $60.5 \%$, safety from traffic (disagreed) 50.8\%, and crime (agreed) 55.6\%. These differences were not significant across gender (all $p>0.05$; Table 2).

3.2. Prevalent Hypertension. A total of 199 participants reported a previous diagnosis of hypertension. Therefore, the overall prevalence of self-reported diagnosed hypertension was $29.7 \%$. Equivalent figures were $33.7 \%$ in women and
$16.8 \%$ in men. The difference in the prevalence of selfreported hypertension between men and women was significant $(p<0.001$ Table 2$)$. Among those with no prior hypertension $(n=472), 248(52.5 \%)$ met the diagnostic threshold for "screen-detected hypertension" while 447 (66.6\%) of the total sample had any hypertension. The prevalence of screendetected hypertension $(p<0.001)$ and "any hypertension" $(p=0.003)$ was always higher in men than in women (Table 2).

Overall, among those with no prior hypertension, the mean blood pressure level was $141.8 \pm 24.2 \mathrm{mmHg}$ (systolic) and $91.9 \pm 14.6 \mathrm{mmHg}$ (diastolic). Equivalent figures were $142.2 \pm 25.7 \mathrm{mmHg}$ (systolic) and $92.7 \pm 15.2 \mathrm{mmHg}$ (diastolic) in women and $140.5 \pm 19.4 \mathrm{mmHg}$ (systolic) and $89.3 \pm$ $12.2 \mathrm{mmHg}$ (diastolic) in men (Table 2). Differences in mean $\mathrm{BP}$ by gender were significant for diastolic blood pressure $(p=0.004)$, but not for systolic blood pressure $(p=0.838$; Table 2).

3.3. Association between Sociodemographic Characteristics, CVD Risk Factors, Perceived Built Environment Attributes, and Self-Reported Hypertension. In general, univariate analysis 
indicates that women were more likely to be at risk of hypertension $(\mathrm{OR}=2.53,95 \% \mathrm{CI}=1.61-3.97)$ compared to their male counterparts. Overall, those aged $45-54$ years (OR $=3.86,95 \% \mathrm{CI}=2.26-6.57$ ) and those aged 55 and above were more likely to be at risk of hypertension than those aged 3544 years $(\mathrm{OR}=9.79,95 \% \mathrm{CI}=5.81-16.48)$. Divorced persons ((relative to the single) results not shown) were more likely to report hypertension $(\mathrm{OR}=2.44,95 \% \mathrm{CI}=1.51-3.94$; Table 3$)$. Urban dwellers were at higher risk of hypertension ( $\mathrm{OR}=$ $2.26,95 \% \mathrm{CI}=1.61-3.16)$ compared to those in rural areas. Those who were overweight $(\mathrm{OR}=2.42,95 \% \mathrm{CI}=1.45-4.04)$ and obese $(\mathrm{OR}=3.43,95 \% \mathrm{CI}=2.21-5.32)$ were at greater risk of hypertension. There was no significant association between PA and hypertension $(p>0.05)$.

3.4. Association between Perceived Built Environment and Self-Reported Hypertension. In the overall sample, the odds of hypertension were significantly higher in persons who reported that distances to neighborhood destinations required walking more than 21 minutes $(\mathrm{OR}=1.96,95 \% \mathrm{CI}$ $=1.51-3.34$; Table 3$)$. Those who perceived that their streets were well connected had lower odds of hypertension (OR $=0.53,95 \% \mathrm{CI}=0.37-0.74)$. Those who perceived their infrastructure was good for walking and cycling (OR = $0.65,95 \% \mathrm{CI}=0.46-0.90)$ and those who perceived their neighborhood aesthetics to be of good quality were less likely to report diagnosed hypertension $(\mathrm{OR}=0.71,95 \% \mathrm{CI}$ $=0.51-0.90)$. Those who perceived their environment to be at risk of crime had higher odds of hypertension $(\mathrm{OR}=1.44$, $95 \% \mathrm{CI}=1.03-2.02)$. Perceived lack of safety from traffic was also significantly associated with hypertension $(\mathrm{OR}=1.46$, $95 \% \mathrm{CI}=1.04-2.03)$.

\subsection{Multivariable Associations of Perceived Built Environ-} ment Attributes with Self-Reported Hypertension. Age, gender, education, location, BMI, and physical activity-adjusted associations between perceived built environment attributes and self-reported hypertension are shown in Table 3. Those who perceived that the distance between their residences and the nearest destination (land use mix-diversity) was more than 21 minutes had higher odds (expected direction) of selfreported hypertension ( $\mathrm{OR}=2.37,95 \% \mathrm{CI}=1.24-4.55)$. However, street connectivity, infrastructure for walking/cycling, aesthetics, and safety from traffic and crime were no longer significantly associated with the outcome $(p>0.05)$.

3.6. Multivariable Associations of Perceived Built Environment with Screen-Detected Hypertension and Any Hypertension. The multivariable associations of perceived built environment attributes with screen-detected hypertension and any hypertension are shown in Table 4. After adjusting for age, gender, education, location, BMI, and physical activity, only perceived lack of safety from traffic was associated with screen-detected hypertension $(\mathrm{OR}=1.89,95 \% \mathrm{CI}=1.07-2.02)$ while other perceived built environment attributes were not statistically significant in both screen-detected hypertension and any hypertension $(p>0.05)$.

\section{Discussion}

The prevalence of hypertension among this sample of urban and rural adult South Africans was high, with nearly onethird reporting existing hypertension and about two-thirds having either self-reported or screen-detected hypertension. In crude logistic regressions, self-reported hypertension was associated with land use-mix, street connectivity, infrastructure for walking/cycling, aesthetics, traffic, and crime. In the adjusted models, land use mix-diversity was significantly associated with self-reported hypertension and to some extent with screen-detected hypertension. Lack of safety from traffic was further associated with screen-detected hypertension. To our knowledge, this is the first study in South Africa that has attempted to explore the association between perceived neighborhood environment attributes and prevalent hypertension.

In our simple logistic regression model, land use mixdiversity (proximity) was associated with hypertension. In another cross-sectional study similar results were found [30]. A possible potential mechanism suggested that the benefit of living near to public facilities would include increased recreational physical activity and seeing others, which encourages the frequency of walking, that in turn lower the risk of developing hypertension. In addition, we observed that street connectivity in the neighborhood was associated with hypertension. There is very scant literature on this field. It has been suggested that research should move beyond evaluating the relationships between the built environment and walking, to chronic disease risk factors and outcomes that relate to walkability as well as more specific characteristics of the built environment [26]. Similarly to our study, other investigators have corresponding results [31]. For instance, Coffee et al. [26] used geographic information system to test the hypothesis that higher walkability index was associated with a lower cardiometabolic risk (CMR) among Australian adults. Their study revealed that a lower CMR score (including hypertension) was associated with higher walkability index. Similarly, Li et al. [32] noted a decrease in systolic and diastolic blood pressure for those living in high walkable neighborhoods. Likewise, Marshall et al. [31] study suggested that more compact and connected street networks with fewer lanes on the major roads were correlated with reduced rates of high blood pressure. A possible explanation for this relationship may be that many alternative routes in the local area increase the possibilities of cycling for recreation or walking which in turn would lower the risk of hypertension.

In our study we found those who perceived that their infrastructure was good for walking and cycling were less likely to be hypertensive which is indicative of healthier lifestyle. One study conducted in USA was in agreement with our study [33]. Likewise, similar results were observed in a cross-sectional study that examined mode and duration of travel to work in rural and urban India and associations between active travel and hypertension [34]. These studies have demonstrated that infrastructure for working and cycling in both low-income countries and high-income countries lowers hypertension risk by promoting walkability. One possible explanation, for instance, is that sidewalk 
TABLE 3: Correlates of self-reported hypertension.

\begin{tabular}{|c|c|c|c|c|c|c|}
\hline \multirow{2}{*}{ Variables } & \multicolumn{3}{|c|}{ Univariable analysis } & \multicolumn{3}{|c|}{ Multivariable analysis } \\
\hline & OR & $95 \% \mathrm{CI}$ & $p$ value & $\mathrm{OR}^{\mathrm{a}}$ & $95 \% \mathrm{CI}$ & $p$ value \\
\hline \multicolumn{7}{|l|}{ Gender } \\
\hline \multicolumn{7}{|l|}{ Male (ref) } \\
\hline Female & 2.53 & $1.61-3.97$ & $<0.001$ & 2.43 & $1.41-4.17$ & $<\mathbf{0 . 0 0 1}$ \\
\hline \multicolumn{7}{|l|}{ Age } \\
\hline \multicolumn{7}{|l|}{$35-44$ (ref) } \\
\hline $45-54$ & 3.86 & $2.26-6.57$ & $<0.001$ & 4.39 & $2.50-7.73$ & $<0.001$ \\
\hline $55+$ & 9.79 & $5.81-16.48$ & $<0.001$ & 11.99 & $6.84-21.01$ & $<0.001$ \\
\hline \multicolumn{7}{|l|}{ Education level } \\
\hline \multicolumn{7}{|l|}{ Primary (ref) } \\
\hline Secondary & 0.73 & $0.33-1.61$ & 0.438 & 0.95 & $0.38-2.38$ & 0.950 \\
\hline Tertiary & 1.20 & $0.41-3.48$ & 0.737 & 1.54 & $0.45-5.26$ & 0.494 \\
\hline \multicolumn{7}{|l|}{ Location } \\
\hline \multicolumn{7}{|l|}{ Rural (ref) } \\
\hline Urban & 2.26 & $1.61-3.16$ & $<0.001$ & 1.74 & $1.03-2.92$ & 0.038 \\
\hline \multicolumn{7}{|l|}{$B M I$} \\
\hline \multicolumn{7}{|l|}{ Normal (ref) } \\
\hline Overweight & 2.42 & $1.45-4.04$ & 0.001 & 2.00 & $1.12-3.58$ & 0.019 \\
\hline Obesity & 3.43 & $2.21-5.32$ & $<0.001$ & 2.21 & $1.32-3.72$ & 0.003 \\
\hline \multicolumn{7}{|c|}{ Physical activity level } \\
\hline \multicolumn{7}{|c|}{$<150 \mathrm{~min} /$ week (ref) } \\
\hline$>150 \mathrm{~min} /$ week & 1.23 & $0.88-1.83$ & 0.203 & 1.16 & $0.75-1.79$ & 0.504 \\
\hline \multicolumn{7}{|c|}{ Land use mix-diversity } \\
\hline \multicolumn{7}{|c|}{$\leq 20 \mathrm{~min}(\mathrm{ref})$} \\
\hline$\geq 21 \mathrm{~min}$ & 1.96 & $1.51-3.34$ & 0.013 & 2.37 & $1.24-4.55$ & 0.009 \\
\hline \multicolumn{7}{|c|}{ Land use mix-access } \\
\hline \multicolumn{7}{|l|}{ Disagree (ref) } \\
\hline Agree & 1.31 & $0.88-1.96$ & 0.182 & 0.79 & $0.43-1.44$ & 0.436 \\
\hline \multicolumn{7}{|c|}{ Street connectivity } \\
\hline \multicolumn{7}{|c|}{ Disagree (ref) } \\
\hline Agree & 0.53 & $0.37-0.74$ & $<0.001$ & 0.64 & $0.35-1.17$ & 0.149 \\
\hline \multicolumn{7}{|c|}{ Infrastructure for walking/cycling } \\
\hline \multicolumn{7}{|l|}{ Disagree (ref) } \\
\hline Agree & 0.65 & $0.46-0.90$ & 0.011 & 0.95 & $0.53-1.72$ & 0.871 \\
\hline \multicolumn{7}{|l|}{ Aesthetics } \\
\hline Disagree (ref) & & & & & & \\
\hline Agree & 0.71 & $0.51-0.90$ & 0.049 & 0.84 & $0.51-1.37$ & 0.479 \\
\hline Safety from traff & & & & & & \\
\hline Disagree (ref) & & & & & & \\
\hline Agree & 1.46 & $1.04-2.03$ & 0.027 & 1.17 & $0.66-2.06$ & 0.599 \\
\hline Safety from crim & & & & & & \\
\hline Disagree (ref) & & & & & & \\
\hline Agree & 1.44 & $1.03-2.02$ & 0.036 & 1.21 & $0.72-2.04$ & 0.469 \\
\hline
\end{tabular}


TABLE 4: Multivariable associations of perceived built environment attribute with screen-detected hypertension and any hypertension.

\begin{tabular}{|c|c|c|c|c|c|c|}
\hline \multirow{2}{*}{ Variables } & \multicolumn{3}{|c|}{ Screen-detected hypertension } & \multicolumn{3}{|c|}{ Any hypertension } \\
\hline & $\mathrm{OR}^{\mathrm{a}}$ & $95 \% \mathrm{CI}$ & $p$ value & $\mathrm{OR}^{\mathrm{a}}$ & $95 \% \mathrm{CI}$ & $p$ value \\
\hline \multicolumn{7}{|l|}{ Gender } \\
\hline \multicolumn{7}{|l|}{ Male (ref) } \\
\hline Female & 0.44 & $0.28-0.68$ & $<0.001$ & 0.47 & $0.29-0.78$ & 0.004 \\
\hline \multicolumn{7}{|l|}{ Age } \\
\hline \multicolumn{7}{|l|}{ 35-44 (ref) } \\
\hline $45-54$ & 1.34 & $0.85-2.09$ & 0.207 & 2.06 & $1.38-3.07$ & $<0.001$ \\
\hline $55+$ & 3.52 & $2.04-6.08$ & $<0.001$ & 7.45 & $4.57-12.16$ & $<0.001$ \\
\hline \multicolumn{7}{|l|}{ Education level } \\
\hline \multicolumn{7}{|l|}{ Primary (ref) } \\
\hline Secondary & 3.93 & $0.73-21.14$ & 0.111 & 3.11 & $0.67-14.48$ & 0.149 \\
\hline Tertiary & 1.12 & $0.34-3.27$ & 0.830 & 0.99 & $0.41-2.36$ & 0.977 \\
\hline \multicolumn{7}{|l|}{ Location } \\
\hline \multicolumn{7}{|l|}{ Rural (ref) } \\
\hline Urban & 2.41 & $1.37-4.24$ & 0.002 & 2.70 & $1.64-4.47$ & $<0.001$ \\
\hline \multicolumn{7}{|l|}{$B M I$} \\
\hline \multicolumn{7}{|l|}{ Normal (ref) } \\
\hline Overweight & 1.41 & $0.85-2.35$ & 0.184 & 1.41 & $0.85-2.35$ & 0.184 \\
\hline Obese & 1.29 & $0.76-2.20$ & 0.347 & 1.29 & $0.76-2.20$ & 0.347 \\
\hline \multicolumn{7}{|c|}{ Physical activity level } \\
\hline \multicolumn{7}{|c|}{$<150 \mathrm{~min} /$ week (ref) } \\
\hline$>150 \mathrm{~min} /$ week & 0.91 & $0.58-1.43$ & 0.691 & 0.99 & $0.66-1.47$ & 0.942 \\
\hline \multicolumn{7}{|c|}{ Land use mix-diversity } \\
\hline \multicolumn{7}{|l|}{$\leq 20 \min ($ ref $)$} \\
\hline$\geq 21 \mathrm{~min}$ & 2.13 & $0.95-4.75$ & 0.065 & 1.26 & $0.67-2.39$ & 0.476 \\
\hline \multicolumn{7}{|c|}{ Land use mix-access } \\
\hline \multicolumn{7}{|l|}{ Disagree (ref) } \\
\hline Agree & 0.98 & $0.55-1.73$ & 0.930 & 1.02 & $0.61-1.72$ & 0.928 \\
\hline \multicolumn{7}{|c|}{ Street connectivity } \\
\hline \multicolumn{7}{|c|}{ Disagree (ref) } \\
\hline Agree & 0.55 & $0.30-1.01$ & 0.053 & 0.72 & $0.42-1.23$ & 0.226 \\
\hline \multicolumn{7}{|c|}{ Infrastructure for walking/cycling } \\
\hline \multicolumn{7}{|l|}{ Disagree (ref) } \\
\hline Agree & 0.55 & $0.50-1.71$ & 0.795 & 0.90 & $0.52-1.55$ & 0.706 \\
\hline \multicolumn{7}{|l|}{ Aesthetics } \\
\hline Disagree (ref) & & & & & & \\
\hline Agree & 1.23 & $0.73-2.09$ & 0.434 & 1.29 & $0.81-2.06$ & 0.285 \\
\hline Safety from traff & & & & & & \\
\hline Disagree (ref) & & & & & & \\
\hline Agree & 1.92 & $1.07-3.43$ & 0.029 & 0.63 & $0.38-1.06$ & 0.079 \\
\hline Safety from crim & & & & & & \\
\hline Disagree (ref) & & & & & & \\
\hline Agree & 1.22 & $0.71-2.008$ & 0.468 & 1.20 & $0.75-1.93$ & 0.446 \\
\hline
\end{tabular}

OR: odds ratios; CI: confidence interval; ${ }^{\text {a }}$ odds ratios adjusted for age, gender, education, location, BMI, and physical activity in the table; bold $p=$ significant borderline. 
buffers provide high walkable environment which indirectly lowers cardiometabolic risk factors such as hypertension. Therefore, individuals living in neighborhoods with high street connectivity are more likely to meet recommended levels of walking. In addition, it has been suggested that walking "physical activity" of light-to-moderate intensity may be a particularly effective method of lowering blood pressure in older adults [35].

Perceived quality aesthetics in our study was associated with lowering hypertension. Limited literature on this relationship has found that those who perceive their aesthetics of good quality have increased their walkability and reduced hypertension risks. For example a study in Taiwan assessed aesthetics in relation to traffic noise and the risk for hypertension [36]. The authors noted that there was an increasing trend in the prevalence of hypertension for those who were exposed to road traffic noise. Similar results have been noted elsewhere $[37,38]$ but not for rail noise [39]. The variations in the results could be due to structural differences in the city developments, traffic density, and air pollution across the studies. However, individuals living in areas with high neighborhood aesthetics are more likely to meet recommended levels of walking [40]. In Nigeria, among young adults, seeing many people active and many interesting things to look at were significantly associated with sufficient walking [16]. Therefore, in the South African context, the population is more likely to walk in the neighborhood that is perceived to be less polluted, as compared to their counterparts in high income countries who may spend most of their time sitting in a motor vehicle each day.

It is worth noting that, in our crude logistic regression analysis, both safety from traffic and safety from crime were associated with hypertension. However, few studies have examined this relationship between crime and hypertension. For instance, in a Positive Action for Today's Health (PATH) trial $(N=409)$ among American adults, the pattern of associations showed greater neighborhood satisfaction related to attenuation of the adverse link between higher perceived neighborhood crime and higher systolic and diastolic blood pressure [41]. Other studies have linked with diastolic blood pressure in adolescents [42]. Likewise, fewer neighborhood problems [43], greater safety [44], and favorable neighborhoods [45] were associated with blood pressure. According to [44], potential hypertension-inducing features of neighborhoods included limited access to resources conducive to healthy lifestyles and an excess of neighborhood stressors. For example, in Brazil, safety was also associated with being active in leisure time [46]. Likewise, in Nigeria perceived safety from crime and safety from traffic were associated with walking [47]; thus being insecure around your neighborhood would limit your walkability which later leads to high risk of hypertension.

In our adjusted model, we noted that participants, who perceived that the proximity of services was generally more than 21 minutes from their homes, had higher odds of hypertension. Other studies have reported similar results concerning odds for hypertension with proximity to major roadway [15] and street foods [48]. One possible explanation apart from physical activity is that the availability of facilities within walkable distance provides access, for example, to retail fruits and vegetables. The implication of the relationship suggests that participants were less likely to engage in leisure related physical activity and were more dependent on motorized transport to get to and from places. In the present study, even after we adjusted for physical activity, BMI was significantly associated (expected direction) with self-reported hypertension. Thus, overweight and obesity, independent of physical activity, may play a major role in hypertension prevalence among the participants in our study.

The study also identified lack of safety from traffic in the neighborhoods was associated with prevalent screendetected hypertension. A previous study conducted in USA was in agreement with our study [33]. Likewise, perceived greater safety in the neighborhood was associated with a lower probability of hypertension [44]. In another metaanalysis, traffic volume on major roads within $100 \mathrm{~m}$ of the residence was associated with increased systolic and diastolic blood pressure [49]. In our current study, we did not find a significant relationship between physical activity and hypertension. For this reason, other factors such interactions of high volume of traffic in urban settings, gender, and age may influence hypertension. Future studies should consider investigating the mediating or moderating factors between safety from traffic and hypertension.

\section{Strengths and Limitations}

Our study had some limitations worth noting. Hypertension status was mostly based on self-reports which is subject to recall bias and risk of reverse causality in the sense that people's perceptions about their environment may change subsequent to hypertension diagnosis [50]. Another limitation of this study was that participation in this study was voluntary as opposed to recruitment of a more generally representative segment of the population. As a result, this study may have missed capturing information from nonparticipants with different knowledge about hypertension and its correlates [51]. This was a cross-sectional design which does not allow for causal relationships to be established. Some strengths of the current study are eminent. The study used a sample that was selected to represent urban and rural communities in South Africa. This study adds to a growing evidence base of scarce studies on the relationship between built environment and hypertension, particularly in African context.

\section{Conclusion}

In the current study, hypertension was highly frequent. Overall, perceived built attributes were associated with prevalent hypertension. In adjusted model, land use mix-diversity and lack of safety from traffic were significantly associated with hypertension. Furthermore, there is need to replicate similar studies using a locally developed tool in African context. 


\section{Disclosure}

Opinions, findings, conclusions, and recommendations expressed are those of the authors and the funders accept no liability in this regard.

\section{Competing Interests}

The authors declare that they have no competing interests.

\section{Authors' Contributions}

Pasmore Malambo and Andre P. Kengne were involved in the conception and design. Pasmore Malambo conducted the analysis and interpretation. Pasmore Malambo and Andre P. Kengne were involved in interpretation and wrote the first draft. Pasmore Malambo, Andre P. Kengne, Estelle V. Lambert, Anniza De Villers, and Thandi Puoane were involved on drafting, revising, and final approval. Andre P. Kengne, Estelle V. Lambert, and Anniza De Villers contributed equally to this work.

\section{Acknowledgments}

The authors would like to thank the Population Health Research Institute, Hamilton Health Sciences, and McMaster University, Hamilton, Canada; the Medical Research Council of South Africa and the National Research Foundation of South Africa for permission to analyse their data. This study was supported by Social Innovation in Public Health Impulse Fellowship Programme. Funding was for analysis, interpretation of data, transport, and accommodation.

\section{References}

[1] World Health Organisation, Non Communicable Disease Country Profile, World Health Organization, Geneva, Switzerland, 2011.

[2] World Health Organisation, World Health Statistics 2012, World Health Organization, Geneva, Switzerland, 2012, http://www .who.int/gho/publications/world_health_statistics/2012/en/.

[3] S. Yusuf, S. Rangarajan, K. Teo et al., "Cardiovascular risk and events in 17 low-, middle-, and high-income countries," The New England Journal of Medicine, vol. 371, no. 9, pp. 818-827, 2014.

[4] P. M. Kearney, M. Whelton, K. Reynolds, P. Muntner, P. K. Whelton, and J. He, "Global burden of hypertension: analysis of worldwide data," The Lancet, vol. 365, no. 9455, pp. 217-223, 2005.

[5] F. X. Gómez-Olivé, M. Thorogood, C. Benjamin, K. Kahn, and S. Tollman, "Self-reported health and health care use in an ageing population in the Agincourt sub-district of rural South Africa," Global Health Action, vol. 6, Article ID 19305, 2013.

[6] O. Shisana, D. Labadarios, T. Rehle et al., "The South African National Health and Nutrition Examination Survey," SANHANES-1, pp. 1-78, 2013.

[7] R. Norman, T. Gaziano, R. Laubsher, K. Steyn, and D. Bradshaw, "Estimating the burden of disease attributable to high blood pressure in South Africa in 2000," South African Medical Journal, vol. 97, no. 8, pp. 692-698, 2007.
[8] S. van de Vijver, H. Akinyi, S. Oti et al., "Status report on hypertension in Africa-consultative review for the 6th Session of the African Union Conference of Ministers of Health on NCD's," The Pan African Medical Journal, vol. 16, article 38, 17 pages, 2013.

[9] F. Ataklte, S. Erqou, S. Kaptoge, B. Taye, J. B. Echouffo-Tcheugui, and A. P. Kengne, "Burden of undiagnosed hypertension in sub-saharan africa: a systematic review and meta-analysis," Hypertension, vol. 65, no. 2, pp. 291-298, 2015.

[10] T. P. Helelo, Y. A. Gelaw, and A. A. Adane, "Prevalence and associated factors of hypertension among adults in Durame Town, Southern Ethiopia," PLoS ONE, vol. 9, no. 11, Article ID el12790, 2014.

[11] A. Cois and R. Ehrlich, "Analysing the socioeconomic determinants of hypertension in South Africa: a structural equation modelling approach," BMC Public Health, vol. 14, article 414, 2014.

[12] T. A. Pearson, L. P. Palaniappan, N. T. Artinian et al., "American Heart Association guide for improving cardiovascular health at the community level, 2013 update: a scientific statement for public health practitioners, healthcare providers, and health policy makers," Circulation, vol. 127, no. 16, pp. 1730-1753, 2013.

[13] J. F. Sallis, M. F. Floyd, D. A. Rodríguez, and B. E. Saelens, "Role of built environments in physical activity, obesity, and cardiovascular disease," Circulation, vol. 125, no. 5, pp. 729-737, 2012.

[14] M. Su, Y.-Y. Tan, Q.-M. Liu et al., "Association between perceived urban built environment attributes and leisure-time physical activity among adults in Hangzhou, China," Preventive Medicine, vol. 66, pp. 60-64, 2014.

[15] K. Kirwa, M. N. Eliot, Y. Wang et al., "Residential proximity to major roadways and prevalent hypertension among postmenopausal women: Results from the women's health initiative San Diego cohort," Journal of the American Heart Association, vol. 3, no. 5, Article ID e000727, 2014.

[16] A. L. Oyeyemi, B. O. Adegoke, A. Y. Oyeyemi, B. Deforche, I. D. Bourdeaudhuij, and J. F. Sallis, "Environmental factors associated with overweight among adults in Nigeria," International Journal of Behavioral Nutrition and Physical Activity, vol. 9, no. 1, article 32, 2012.

[17] World Health Organization, "World medical association declaration of Helsinki," Bulletin of the World Health Organization, vol. 79, no. 4, pp. 373-374, 2001.

[18] K. Teo, C. K. Chow, M. Vaz, S. Rangarajan, and S. Yusuf, "The Prospective Urban Rural Epidemiology (PURE) study: examining the impact of societal influences on chronic noncommunicable diseases in low-, middle-, and high-income countries," American Heart Journal, vol. 158, no. 1, pp. 1-7.el, 2009.

[19] C. K. Chow, K. Lock, M. Madhavan et al., "Environmental profile of a community's health (EPOCH): an instrument to measure environmental determinants of cardiovascular health in five countries," PLoS ONE, vol. 5, no. 12, article e14294, 2010.

[20] World Health Organization, Obesity: Preventing and Managing the Global Epidemic. Report of a WHO Consultation on Obesity, WHO, Geneva, Switzerland, 2000.

[21] T. G. Pickering, J. E. Hall, L. J. Appel et al., "Recommendations for blood pressure measurement in humans: an AHA scientific statement from the Council on High Blood Pressure Research Professional and Public Education Subcommittee," Journal of Clinical Hypertension, vol. 7, no. 2, pp. 102-109, 2005. 
[22] P. C. Hallal, R. S. Reis, D. C. Parra, C. Hoehner, R. C. Brownson, and E. J. Simoes, "Association between perceived environmental attributes and physical activity among adults in Recife, Brazil," Journal of Physical Activity and Health, vol. 7, no. 2, pp. S213S222, 2010.

[23] World Health Organisation, Global Recommendations on Physical Activity for Health, World Health Organization, Geneva, Switzerland, 2010.

[24] P. C. Hallal, L. B. Andersen, F. C. Bull et al., "Global physical activity levels: surveillance progress, pitfalls, and prospects," The Lancet, vol. 380, no. 9838, pp. 247-257, 2012.

[25] E. G. Bengoechea, J. C. Spence, and K. R. McGannon, “Gender differences in perceived environmental correlates of physical activity," International Journal of Behavioral Nutrition and Physical Activity, vol. 2, article 12, 2005.

[26] N. T. Coffee, N. Howard, C. Paquet, G. Hugo, and M. Daniel, "Is walkability associated with a lower cardiometabolic risk?" Health and Place, vol. 21, pp. 163-169, 2013.

[27] T. Sugiyama, E. Cerin, N. Owen et al., "Perceived neighbourhood environmental attributes associated with adults[U+05F3] recreational walking: IPEN Adult study in 12 countries," Health and Place, vol. 28, pp. 22-30, 2014.

[28] B. E. Saelens, J. F. Sallis, and L. D. Frank, "Environmental correlates of walking and cycling: findings from the transportation, urban design, and planning literatures," Annals of Behavioral Medicine, vol. 25, no. 2, pp. 80-91, 2003.

[29] G. L. Schlomer, S. Bauman, and N. A. Card, "Best practices for missing data management in counseling psychology," Journal of Counseling Psychology, vol. 57, no. 1, pp. 1-10, 2010.

[30] R. Grazuleviciene, A. Dedele, A. Danileviciute et al., "The influence of proximity to city parks on blood pressure in early pregnancy," International Journal of Environmental Research and Public Health, vol. 11, no. 3, pp. 2958-2972, 2014.

[31] W. E. Marshall, D. P. Piatkowski, and N. W. Garrick, "Community design, street networks, and public health," Journal of Transport and Health, vol. 1, no. 4, pp. 326-340, 2014.

[32] F. Li, P. Harmer, B. J. Cardinal, and N. Vongjaturapat, "Built environment and changes in blood pressure in middle aged and older adults," Preventive Medicine, vol. 48, no. 3, pp. 237-241, 2009.

[33] R. E. Lee, S. K. Mama, and H. J. Adamus-Leach, "Neighborhood street scale elements, sedentary time and cardiometabolic risk factors in inactive ethnic minority women," PLoS ONE, vol. 7, no. 12, Article ID e51081, 2012.

[34] C. Millett, S. Agrawal, R. Sullivan et al., "Associations between active travel to work and overweight, hypertension, and diabetes in India: a cross-sectional study," PLoS Medicine, vol. 10, no. 6, Article ID e1001459, 2013.

[35] P. D. Reaven, E. Barrett-Connor, and S. Edelstein, "Relation between leisure-time physical activity and blood pressure in older women," Circulation, vol. 83, no. 2, pp. 559-565, 1991.

[36] T. Y. Chang, R. Beelen, S. F. Li et al., "Road traffic noise frequency and prevalent hypertension in Taichung, Taiwan: a cross-sectional study," Environmental Health, vol. 13, no. 1, p. 37, 2014.

[37] W. Babisch, K. Wolf, M. Petz, J. Heinrich, J. Cyrys, and A. Peters, "Associations between traffic noise, particulate air pollution, hypertension, and isolated systolic hypertension in adults: the KORA study," Environmental Health Perspectives, vol. 122, no. 5, pp. 492-498, 2014.
[38] D. Banerjee, P. P. Das, and A. Fouzdar, "Urban residential road traffic noise and hypertension: a cross-sectional study of adult population," Journal of Urban Health, vol. 91, no. 6, pp. 1144-1157, 2014.

[39] M. Sørensen, M. Hvidberg, B. Hoffmann et al., "Exposure to road traffic and railway noise and associations with blood pressure and self-reported hypertension: a cohort study," Environmental Health, vol. 10, article 92, pp. 1-11, 2011.

[40] J. Pelclová, K. Frömel, and R. Cuberek, "Gender-Specific associations between perceived neighbourhood walkability and meeting walking recommendations when walking for transport and recreation for Czech inhabitants over 50 years of age," International Journal of Environmental Research and Public Health, vol. 11, no. 1, pp. 527-536, 2013.

[41] S. M. Coulon, D. K. Wilson, K. A. Alia, and M. L. Van Horn, "Multilevel associations of neighborhood poverty, crime, and satisfaction with blood pressure in African-American adults," American Journal of Hypertension, vol. 29, no. 1, pp. 90-95, 2016.

[42] S. M. Martinez, E. Blanco, J. Delva et al., "Perception of neighborhood crime and drugs increases cardiometabolic risk in Chilean adolescents," Journal of Adolescent Health, vol. 54, no. 6, pp. 718-723, 2014.

[43] T. L. Gary, M. M. Safford, R. B. Gerzoff et al., "Perception of neighborhood problems, health behaviors, and diabetes outcomes among adults with diabetes in managed care: The Translating Research Into Action for Diabetes (TRIAD) study," Diabetes Care, vol. 31, no. 2, pp. 273-278, 2008.

[44] M. S. Mujahid, A. V. Diez Roux, J. D. Morenoff, T. E. Raghunathan, R. S. Cooper, H. Ni et al., "Neighborhood characteristics and hypertension," Epidemiology, vol. 19, no. 4, pp. 590-598, 2008.

[45] V. L. Brown, The assessment of cardiovascular disease risk in relation to the built environment and race [Ph.D. thesis], University of Pittsburgh, Pittsburgh, Pa, USA, 2010.

[46] M. W. Corseuil, P. C. Hallal, H. X. Corseuil, I. Jayce Ceola Schneider, and E. d'Orsi, "Safety from crime and physical activity among older adults: a population-based study in Brazil," Journal of Environmental and Public Health, vol. 2012, Article ID 641010, 7 pages, 2012.

[47] A. L. Oyeyemi, B. O. Adegoke, J. F. Sallis, A. Y. Oyeyemi, and I. De Bourdeaudhuij, "Perceived crime and traffic safety is related to physical activity among adults in Nigeria," BMC Public Health, vol. 12, no. 1, article 294, 2012.

[48] T. Dubowitz, M. Ghosh-Dastidar, C. Eibner et al., "The women's health initiative: the food environment, neighborhood socioeconomic status, BMI, and blood pressure," Obesity, vol. 20, no. 4, pp. 862-871, 2012.

[49] K. B. Fuks, G. Weinmayr, M. Foraster et al., "Arterial blood pressure and long-term exposure to traffic-related air pollution: an analysis in the European Study of Cohorts for Air Pollution Effects (ESCAPE)," Environmental Health Perspectives, vol. 122, no. 9, pp. 896-905, 2014.

[50] C. Berry-Caban, "Self-reported Hypertension on a Caribbean Island," Journal of Clinical Medicine Research, vol. 1, no. 1, pp. 17-23, 2009.

[51] G. J. Dave, D. L. Bibeau, M. R. Schulz et al., "Predictors of congruency between self-reported hypertension status and measured blood pressure in the stroke belt," Journal of the American Society of Hypertension, vol. 7, no. 5, pp. 370-378, 2013. 


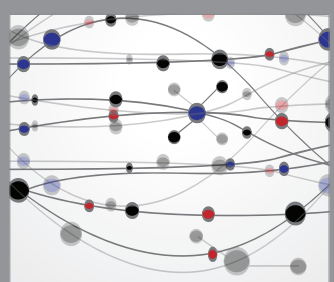

The Scientific World Journal
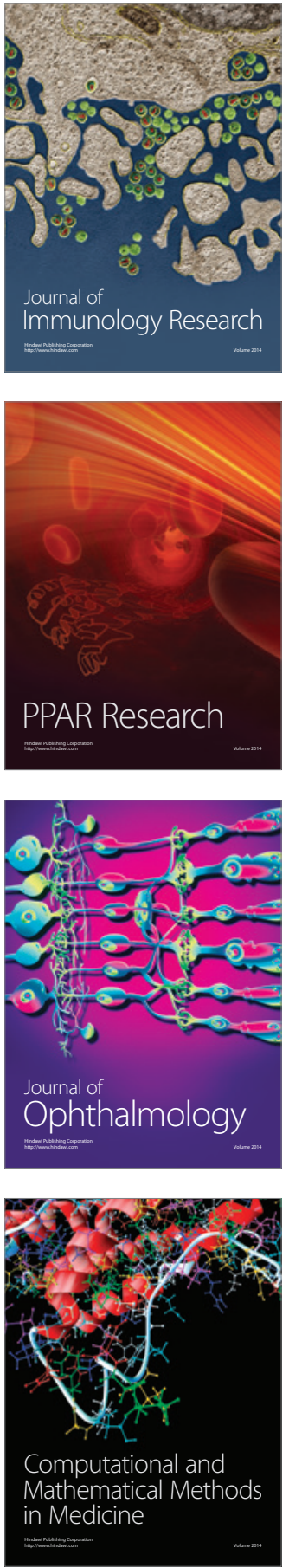

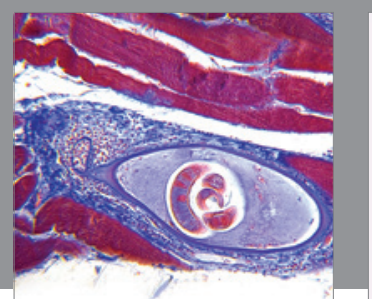

Gastroenterology Research and Practice

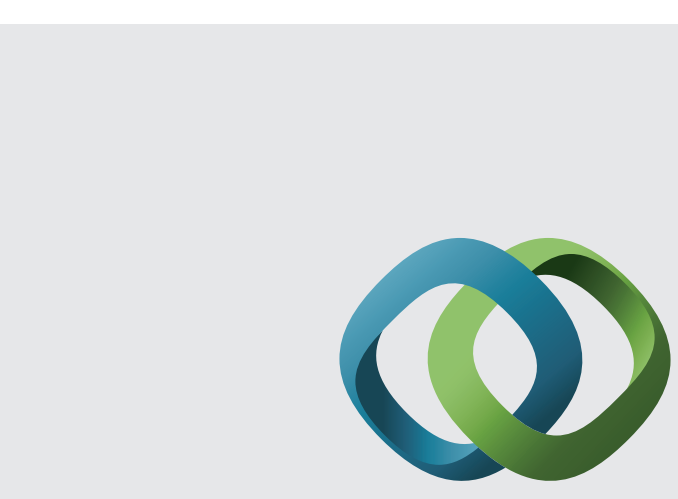

\section{Hindawi}

Submit your manuscripts at

http://www.hindawi.com
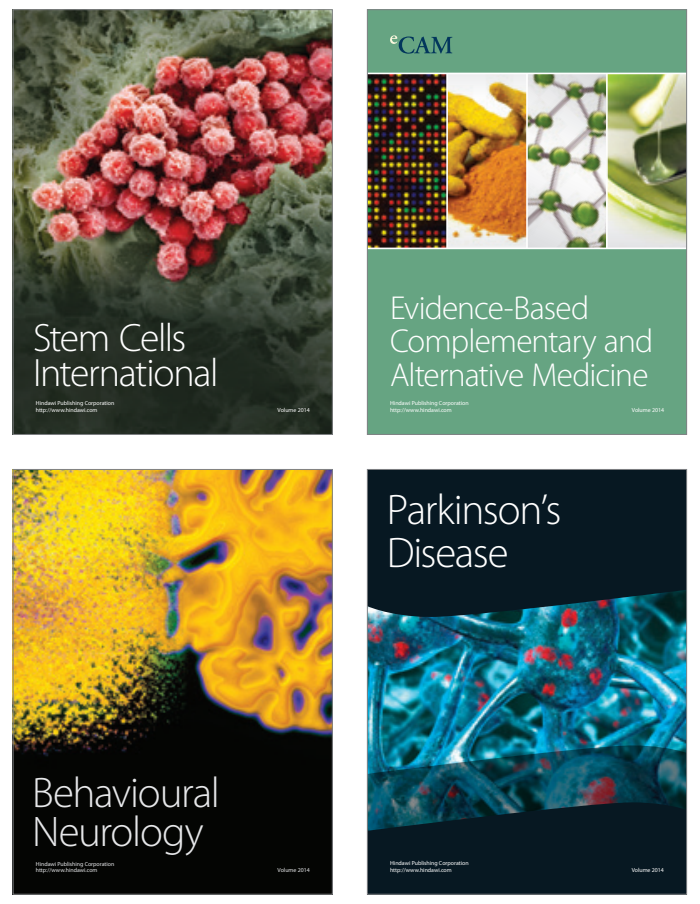
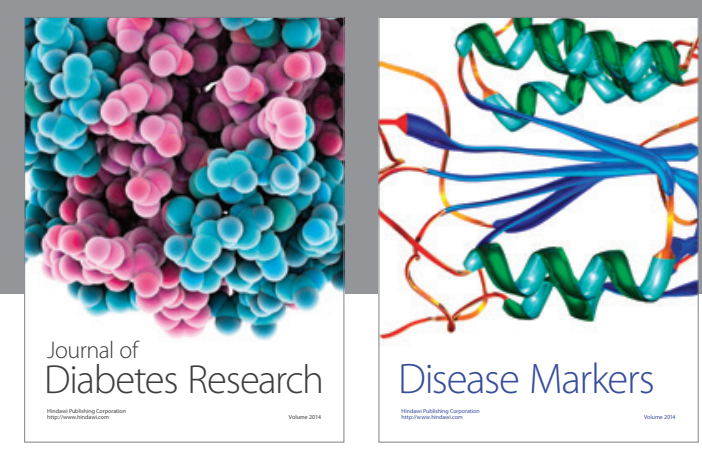

Disease Markers
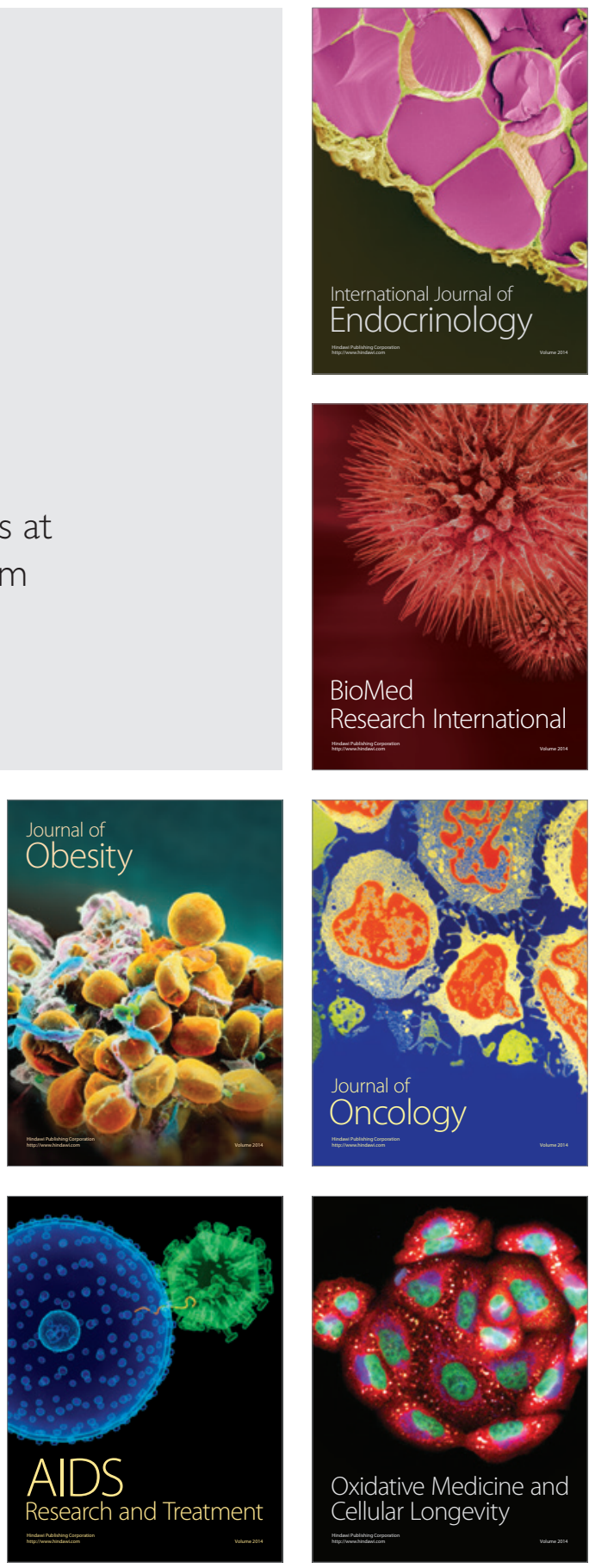